\title{
CONDUTIVIDADE TÉRMICA EM ROCHAS SILICÁTICAS CRISTALINAS, COM ÊNFASE A ROCHAS GRANÍTICAS DA PROVÍNCIA BORBOREMA, NE DO BRASIL, E SUA CORRELAÇÃO COM PARÂMETROS PETROGRÁFICOS E TEXTURAIS
}

\author{
Edgar Romeo H. Figueiredo ${ }^{1}$, Antonio C. Galindo², José Antonio M. Moreira ${ }^{3}$ e Fernando Antonio P.L. Lins ${ }^{4}$ \\ Recebido em 18 junho, 2007 / Aceito em 25 agosto, 2008 \\ Received on June 18, 2007 / Accepted on August 25, 2008
}

\begin{abstract}
This work focuses on rock thermal conductivity $(\lambda)$ and its correlation with petrographic and textural aspects especially in granitic rocks. We demonstrate the role of these variables in order to shed some light in the behavior of conductive heat transfer in rocks. Our results demonstrate clear correlation between $\lambda$ and abundance of quartz and mafic minerals. We show that there is a positive linear correlation between $\lambda$ and quartz content. $0 n$ the other hand, we show there a decrease on $\lambda$ with mafic minerals increase. We found that the relation between $\lambda$ and quartz content may be divided into two sets. The first set are mostly comprised of samples with more than $20 \%$ of quartz exhibiting systematically larger $\lambda$ values ranging from $2,5 \mathrm{~W} / \mathrm{mK}$; the second set comprising samples with less than $20 \%$ quartz content have an average $\lambda$ below $2,5 \mathrm{~W} / \mathrm{mK}$. Regarding textural aspects, we verified that rocks considered thick/porphyry textures generally showed better correlations between $\lambda$ and mineral content (quartz) when compared to rocks considered thin/medium. Therefore, our results clearly indicate that the associated usage of petrophysical measurements such as $\lambda$ with petrographic and textural information can be used to characterize rocks.
\end{abstract}

Keywords: thermal conductivity, physical parameter, petrography, texture.

RESUMO. Este trabalho apresenta e discute medidas de condutividade térmica $(\lambda)$ em rochas silicáticas cristalinas e sua correlação com aspectos petrográficos e texturais, com maior ênfase para as rochas graníticas. 0 intuito é demonstrar as relações destas variáveis tentando elucidar o comportamento da transferência de calor em rochas. Os resultados demonstraram haver boas correlações com o teor de quartzo e os minerais máficos. A correlação linear entre a mineralogia e a condutividade térmica revelou uma relação positiva do aumento de $\lambda$ em função do aumento da percentagem de quartzo e diminuição com o aumento de minerais máficos. A relação do quartzo fica mais evidente quando são comparados os conjuntos de amostras com $>20 \%$ e $<20 \%$. 0 conjunto com mais de $20 \%$ de quartzo exibe, em sua grande maioria, valores de $\lambda$ que variam acima de $2,5 \mathrm{~W} / \mathrm{mK}$, já o conjunto com menos de $20 \%$ tem valores médios de $\lambda$ abaixo de $2,5 \mathrm{~W} / \mathrm{mK}$. Quanto aos aspectos texturais verificou-se que os litotipos considerados grossos/porfiríticos demonstraram, no conjunto geral, melhores correlações entre $\lambda$ e 0 conteúdo de quartzo quando comparados com os litotipos considerados finos/médios. Dessa forma, nossos resultados mostram que existe uma relação estreita entre parâmetros físicos (condutividade térmica, por exemplo) e petrográficos (mineralógicos e texturais) na caracterização petrofísica de rochas.

Palavras-chave: condutividade térmica, parâmetros físicos, petrografia, textura.

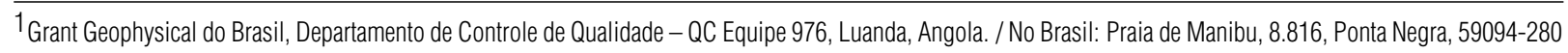
Natal, RN, Brasil. E-mail: romeoufrn@hotmail.com

Programa de Pós-Graduação em Geodinâmica e Geofísica, Departamento de Geologia, Centro de Ciências Exatas e da Terra, Universidade Federal do Rio Grande do Norte, PPGG-UFRN, Cx. Postal 1596, Campus Universitário, 59078-970 Natal, RN, Brasil.

E-mails: ${ }^{2}$ galindo@geologia.ufrn.br /32moreira@dfte.ufrn.br / ${ }^{4}$ flins@geologia.ufrn.br
} 


\section{INTRODUÇÃO}

A condutividade térmica das rochas é um tema relativamente complexo, pois depende de vários fatores dentre eles se destacam a mineralogia, composição química, porosidade, tipo de fluido no espaço poroso, densidade, pressão, temperatura, textura, estrutura, grau de consolidação, grau de alteração etc. Uma rocha é constituída por um agregado de minerais, cada um com valores característicos (ou intervalo) de condutividade térmica, portanto é de se esperar que ao se variar as proporções entre os minerais, a condutividade também apresentará modificações, mostrando uma complexa interação de variáveis.

\section{OBJETIVOS}

0 intuito desse trabalho é realizar, a partir de uma análise petrográfica macro e microscópica de rochas silicáticas cristalinas (quer sejam ígneas ou metamórficas), em especial as de composição granítica, uma comparação com os resultados obtidos de condutividade térmica, correlacionando-os com a mineralogia e a textura da rocha. 0 conhecimento dessas correlações são importantes para um melhor entendimento do comportamento dos diversos litotipos estudados diante dos processos de transferência de calor, podendo ser úteis em várias aplicações como, por exemplo, no entendimento e aferição de resultados de fluxos térmicos regionais, na predição do comportamento térmico de rochas baseados na textura e mineralogia, no segmento de construção civil com o objetivo de fornecer informações mais precisas no que diz respeito ao refinamento de dados sobre condutividade térmica e, ainda, na indústria de rochas ornamentais com 0 intuito de se abrir uma discussão sobre a utilização das variáveis térmicas como novos parâmetros tecnológicos diretamente relacionados ao conforto térmico.

Quando 0 tema é condutividade térmica a literatura especializada contribui muito pouco em termos qualitativos, principalmente quando se trata de "rochas", pois quase sempre os minerais são privilegiados em todos os casos, fornecendo apenas dados quantitativos. A idéia é correlacionar parâmetros quantitativos (dados numéricos) com os qualitativos (textura, tamanho do grão, mineralogia etc.) que serão avaliados, a partir de superfícies polidas e seções delgadas (lâminas) de rochas tentando entender e definir o intervalo de variação da condutividade térmica numa mesma amostra e para grupos de rochas (granodioritos, granitos, monzonitos, sienitos etc.).

\section{CONDUTIVIDADE TÉRMICA}

Os três mecanismos essenciais de transporte do calor são: radiação, convecção e a condução. 0 transporte radiativo de calor faz-se através do espaço sob a forma de ondas eletromagnéticas.
0 transporte por convecção é o mecanismo geralmente mais importante quando o meio que the serve de suporte é um fluido. A transmissão de calor por condução é característica do transporte através dos sólidos. As entidades responsáveis por este transporte são os elétrons de condução e/ou as vibrações da rede cristalina, Incropera \& Witt (1981).

A condutividade térmica $\lambda$ é definida como: $Q=-\lambda \nabla T$, onde $Q$ é o fluxo de calor produzido pelo gradiente de temperatura $\nabla T$

\section{MATERIAIS E MÉTODOS}

As várias técnicas de medida de parâmetros térmicos dividemse em duas categorias principais, são elas: regime dinâmico e regime estacionário. As técnicas dinâmicas (transientes) podem ser usadas para a determinação da difusividade térmica e da condutividade térmica. Para tal, faz-se necessário o conhecimento do tempo para o distúrbio se propagar por uma distância conhecida. Nas técnicas estacionárias o conhecimento do fluxo de calor e do gradiente de temperatura são indispensáveis para a obtenção da condutividade térmica. As técnicas dinâmicas (variação temporal de temperatura) requerem pouco tempo na realização das medidas, porém os resultados são um pouco menos precisos, possuindo em torno de $10 \%$ de erro. Nas técnicas estacionárias, as medidas possuem melhor precisão, em torno de $5 \%$ de erro, mas para atingir o regime estacionário leva-se tempo, tornando o processo muito mais lento e caro. Utilizou-se no presente trabalho um medidor de propriedades térmicas (condutividade térmica, difusividade térmica e capacidade térmica volumétrica) da marca Anter Corporation, modelo Quickline ${ }^{\mathrm{TM}}{ }_{-} 30$, equipamento similar ao utilizado por outros laboratórios nacionais (vide Gomes \& Hamza, 2005) cuja operação é baseada no método transiente utilizando uma fonte planar.

A técnica em regime transiente, além de ser mais rápida, permite a determinação não só da condutividade térmica como também da difusividade $\kappa$. Conseqüentemente a capacidade térmica volumétrica $\rho c$ (produto da densidade $\rho$ pelo calor específico $c$ ) também pode ser obtida, uma vez que a difusividade $\kappa$ é 0 quociente entre a condutividade e a capacidade térmica $(\kappa=\lambda / \rho c)$.

A evolução temporal da temperatura na distância $x$ devido a uma fonte planar contínua de calor situada na distância $x^{\prime}$ é dada por:

$$
\begin{aligned}
T= & Q\left(\frac{t}{\pi \kappa}\right)^{1 / 2} \exp \left(-\frac{\left(x-x^{\prime}\right)^{2}}{4 \kappa t}\right) \\
& -\frac{Q\left|x-x^{\prime}\right|}{2 \lambda} \operatorname{erfc}\left(\frac{\left|x-x^{\prime}\right|}{2 \sqrt{\kappa t}}\right)
\end{aligned}
$$




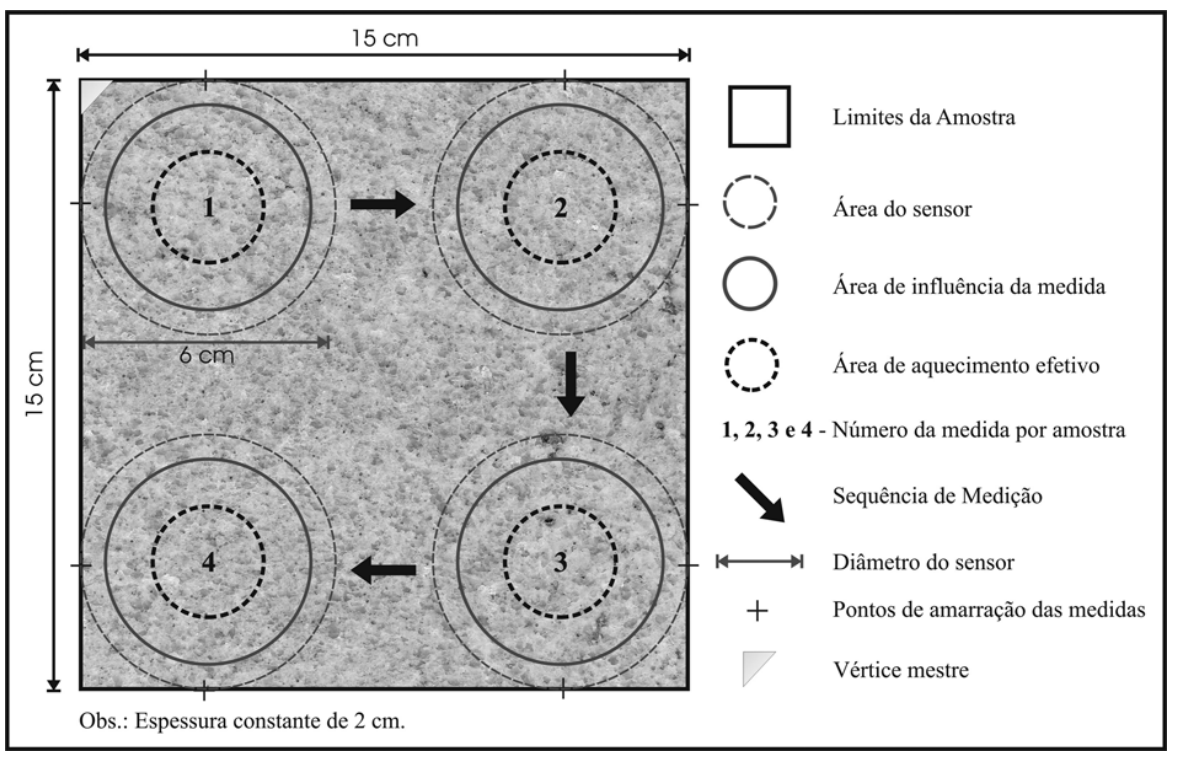

Figura 1 - Procedimento de aquisição dos dados de condutividade térmica.

onde $Q$ é a potência por unidade de área da fonte planar de calor, e $\operatorname{erf} c$ representa a função complementar do erro.

Para os ensaios de condutividade térmica foram selecionadas 93 amostras, sendo que 55 são amostras polidas de rochas silicáticas cristalinas utilizadas com fins ornamentais (denominadas genericamente de Granitos Ornamentais, quer sejam rochas ígneas ou metamórficas), no mercado brasileiro (principalmente no nordeste - BA, PE, PB, RN e CE) e secundariamente no mercado internacional, adquiridas em marmorarias da cidade de Natal, e 38 são amostras de rochas graníticas da Província Borborema, nos domínios Rio Grande do Norte e Ceará. Estas amostras possuem em média $15 \times 15 \times 2 \mathrm{~cm}$, assim dimensionadas de forma a permitir pelo menos 4 medidas em locais distintos (Fig. 1).

0 passo inicial foi demarcar arbitrariamente 0 vértice mestre, ponto de partida para determinação dos demais parâmetros. Como apresentado na Figura 1, a posição desse vértice é fixa localizada na porção superior e do lado esquerdo da amostra. A partir desse vértice foram determinadas as 4 regiões onde seriam realizadas as medidas, sendo estas auxiliadas pelos pontos de amarração (tangente às bordas da amostra). 0 procedimento de aquisição dos dados foi realizado no sentido horário e repetido em todas as amostras, de forma que é possível realizar novas medidas para controle e/ou verificação dos resultados e ainda avaliar quais foram as possíveis variáveis (fase mineral, fissuramentos etc.) que mais influenciaram os resultados. Os pontos de amarração de cada medida foram marcados sempre tangentes às bordas da amostra, totalizado 8 pontos de amarração, sendo dois por medida (Fig. 1).
0 equipamento de medição foi calibrado pelo fabricante, procedimento realizado anualmente pelo Laboratório de Condutividade Térmica do Programa de Pós-Graduação em Geodinâmica e Geofísica-PPGG, da Universidade Federal do Rio Grande do Norte-UFRN, utilizando-se como referência os padrões de pirex, grafite e pirocerâmica, com valores de condutividade de $1,09 \mathrm{~W} / \mathrm{mK}, 2,05 \mathrm{~W} / \mathrm{mK}$ e $4,04 \mathrm{~W} / \mathrm{mK}$, respectivamente, apresentando incertezas de $\pm 6,0 \%$.

$\mathrm{Na}$ tentativa de avaliar a capacidade do sistema experimental em reproduzir os resultados foram efetuadas medições repetidas para um conjunto de 15 amostras, selecionadas aleatoriamente. A fim de minimizar efeitos oriundos da heterogeneidade de materiais geológicos os ensaios de repetição foram realizados no mesmo local da amostra. Os resultados indicam pequenas variações que ficaram na segunda casa decimal, portanto, dentro da margem de erro de $3 \%$, proposto pelo fabricante do equipamento utilizado.

Para se entender a natureza das relações entre as características texturais e petrográficas e a condutividade térmica foram realizadas avaliações macro e microscópicas, e levou-se em consideração possíveis implicações, tais como, tamanho do grão, fissuramentos, mineralogia e alterações (oxidação etc.). A abordagem realizada aqui trata principalmente de aspectos da superfície, mas convém notar que estes aspectos também são relacionados com a natureza tridimensional da condutividade térmica. É importante salientar que as avaliações e interpretações levaram em consideração 0 erro máximo do equipamento (0,2 W/mK aproximadamente). Baseado em informações do fabricante e testes realizados em algumas amostras sugere-se que 
os resultados são representativos de material até a profundidade (espessura) de $1 \mathrm{~cm}$ aproximadamente, limite levado em consideração aqui.

A composição modal de cada amostra foi determinada a partir do estudo de lâminas delgadas ao microscópio petrográfico polarizante e contagem de pontos, por meio de um contador de pontos automático de marca SWIFIT, segundo procedimentos usuais de estudos petrográficos (Hutchison, 1974). Para cada amostra foram confeccionadas duas (2) lâminas delgadas, e contados 1000 pontos por lâmina. Dessa forma foram obtidos os percentuais modais de quartzo, K-feldspato, plagioclásio e máficos (aí incluindo minerais como piroxênios, anfibólios, micas, titanita, opacos etc.). Os valores modais de cada fase mineral foram correlacionados com a condutividade térmica de cada amostra, e a composição modal total de cada amostra serviu para a classificação/nomenclatura das mesmas. Para as rochas ígneas utilizou-se a nomenclatura de Streckeisen (1976) e para as rochas metamórficas a de Winkler (1977).

\section{ASPECTOS MACROSCÓPICOS}

Levando-se em consideração as características de homogeneidade/heterogeneidade textural e petrográfica das amostras estudadas, foram selecionadas sete (7) chapas polidas de granitos ornamentais (amostras com dimensões de $15 \times 15 \times 2 \mathrm{~cm}$ ) para uma avaliação dos aspectos macroscópicos versus condutividade térmica. Duas amostras são de textura isotrópica e homogênea (uma de granulação fina e outra grossa), duas de caráter textural heterogêneo (textura porfirítica), mas ainda isotrópicas, uma de textura homogênea e isotrópica, de granulação fina/média, mas com fortes processos de alterações secundárias, e duas amostras de textura fina/média anisotrópica e de caráter gnáissico. Desse conjunto foram selecionadas quatro (4), as que mostraram resultados mais expressivos, para apresentação neste trabalho (granitos ornamentais Cinza Elite, Branco Dallas, Dourado Carioca e Juparaíba - Tab. 1).

Tabela 1 - Amostras selecionadas para discussão dos parâmetros macroscópicos.

\begin{tabular}{|c|c|c|c|}
\hline Amostras & $\lambda$ & Nome petrográfico & Nome comercial \\
\hline A01 & $2,61 \pm 0,04$ & Tonalito & Cinza Elite \\
\hline A04 & $3,12 \pm 0,13$ & Sienogranito & Branco Dallas \\
\hline A07 & $3,08 \pm 0,26$ & Monzogranito & Dourado Carioca \\
\hline A36 & $3,15 \pm 0,30$ & Monzogranito & Juparaíba \\
\hline
\end{tabular}

Obs.: $\lambda$ (condutividade térmica).

\section{Cinza Elite (A01)}

Composicionalmente este granito ornamental é um tonalito leucocrático de textura fanerítica fina/média e isotrópica (sem orientação preferencial dos minerais), que apresenta cristais equigranulares finos a médios. Mineralogicamente é constituída por plagioclásio (48\%), quartzo (32,7\%), K-feldspato (5,8\%), biotita $(8,8 \%)$, opacos $(1,9 \%)$ e outros (titanita, apatita, zircão e minerais de alteração - 2,8\%). Os valores obtidos foram de 2,54, 2,61, 2,63 e 2,65 W/mK, sendo que o valor médio é de 2,61 \pm $0,04 \mathrm{~W} / \mathrm{mK}$. Nota-se que a variação dos resultados é pequena em relação ao erro máximo do equipamento, refletindo a homogeneidade e textura isotrópica da amostra (Fig. 2).

\section{Branco Dallas (A04)}

Este granito ornamental é uma rocha gnáissica leucocrática, holocristalina, inequigranular, apresentando porfiroblastos de granada dispersos que chegam a atingir $1 \mathrm{~cm}$ segundo eixo maior. A granulometria da matriz mostra-se fina a média, com algumas regiões apresentando maiores concentrações de quartzo. A assembléia mineral é constituída por K-feldspato (42,3\%), quartzo (32,1\%), plagioclásio (14,8\%), granada $(5,7 \%)$, biotita, $(3,9 \%)$ e sillimanita (1,2\%). Composicionalmente a rocha é um "granada gnaisse sienogranítico", e possui alta condutividade, com valor médio de 3,12 $\pm 0,13 \mathrm{~W} / \mathrm{mK}$

Os valores medidos de condutividade térmica foram de 3,02, 3,34, 3,03 e 3,08 W/mK, nas regiões 1, 2, 3 e 4, respectivamente (Fig. 3). Especialmente na medida "2", onde ocorre um cristal de granada, a condutividade é $3,34 \mathrm{~W} / \mathrm{mK}$, aumento relativo de $10 \%$ em relação as demais medidas. Apesar de ser observada ainda na região "1" uma granada anédrica, na região "2" a granada mostra-se mais bem formada e ocupando uma considerável área do sensor, o que explica o aumento da condutividade térmica nesta região. Dados da literatura mostram que granadas apresentam valores altos de condutividade térmica, variando na faixa de 3,3 a 5,5 W/mK (Horai, 1971; Diment \& Pratt, 1988).

\section{Dourado Carioca (A07)}

Constitui-se numa rocha leucocrática, holocristalina, inequigranular, de textura porfirítica, apresentando pórfiros de K-feldspatos dispersos numa matriz de granulometria média. Os pórfiros chegam a atingir $4 \mathrm{~cm}$ segundo eixo maior. Sua mineralogia principal é constituída por K-feldspato (38,2\%), plagioclásio $(24,4 \%)$ quartzo (22,8\%), biotita, (10,9\%), e outros (3,7\%). Composicionalmente a rocha é um monzogranito.

A condutividade térmica média é de $3,08 \pm 0,26 \mathrm{~W} / \mathrm{mK}$, e as regiões 1, 2, 3 e 4 mostram valores de 3,33, 3,21, 2,65 e 3,12 W/mK, respectivamente. No local correspondente a medida "3", a condutividade térmica é 2,65 W/mK (Fig. 4). Neste setor da amostra ocorre um aglomerado de pórfiros de K-feldspato circundando uma região da matriz da rocha rica em cristais de quartzo, feldspato e mica. A variação na condutividade térmica neste lo- 

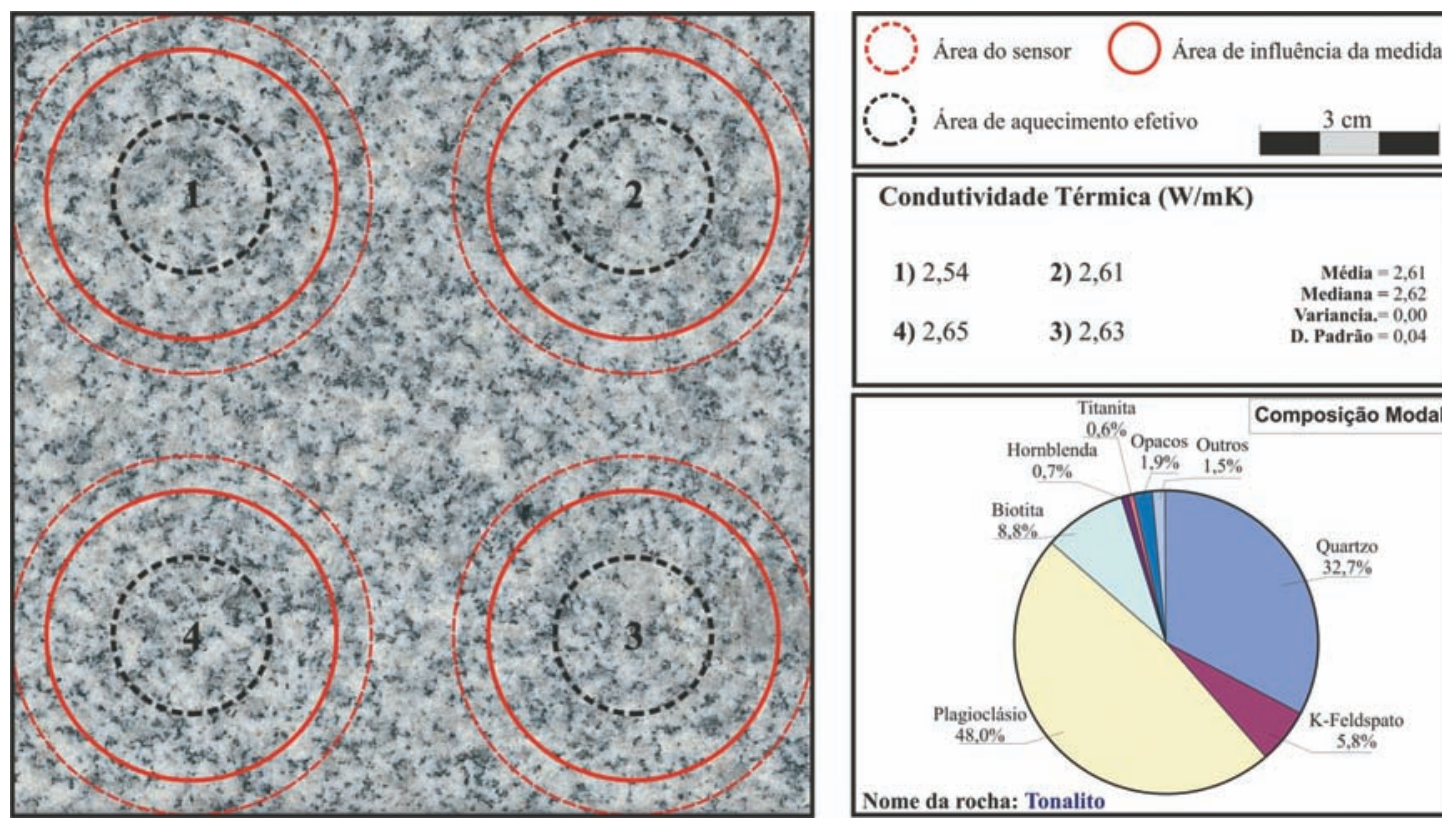

Condutividade Térmica $(\mathrm{W} / \mathrm{mK})$
1) 2,54
2) 2,61
4) 2,65
3) 2,63
Média $=2,61$ Variancia. $=0,00$

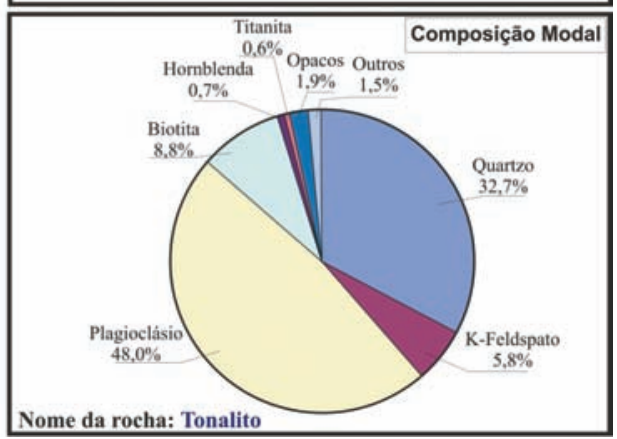

Figura 2 - Granito ornamental Cinza Elite e as medidas de condutividade térmica.
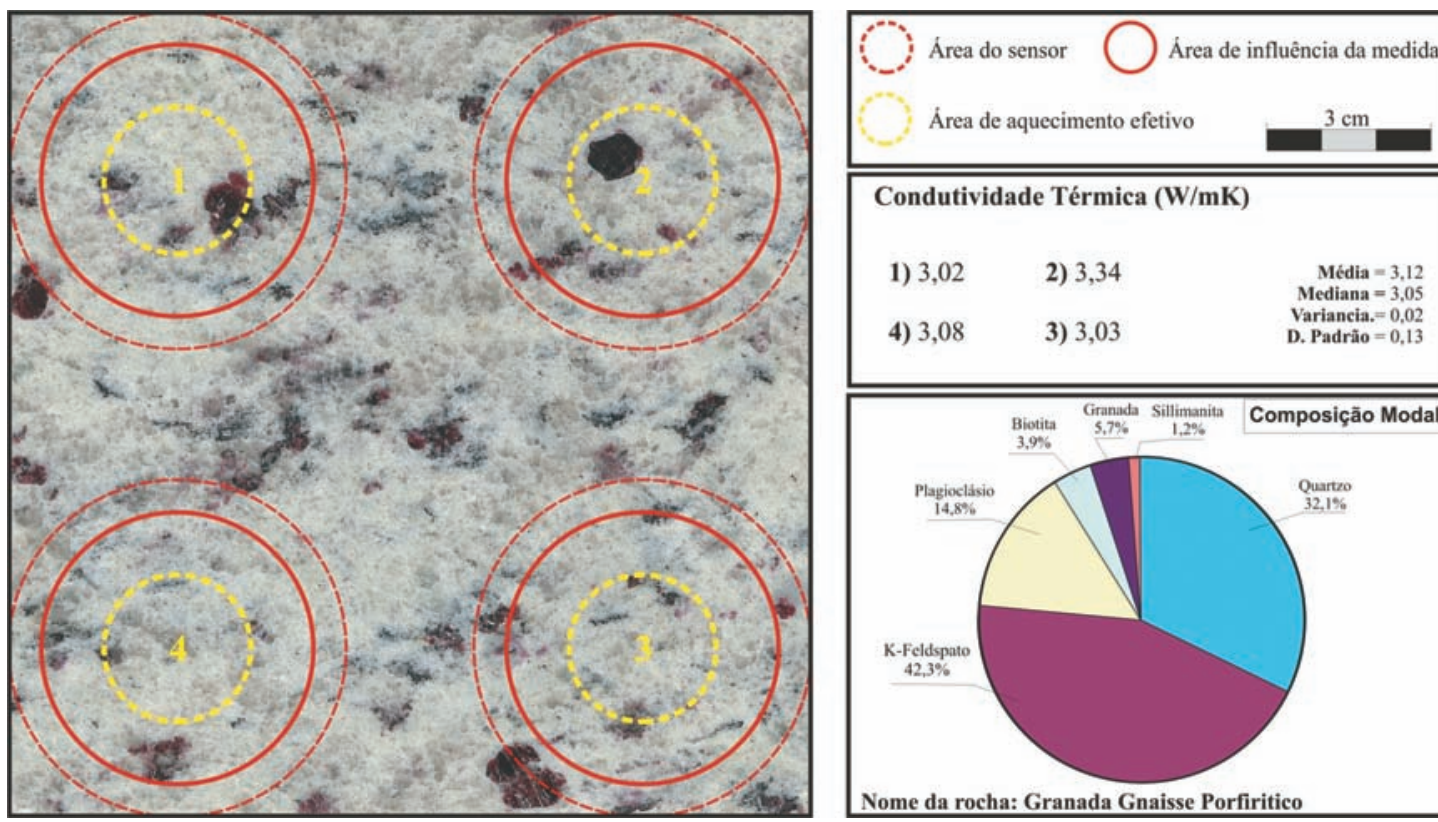

Condutividade Térmica $(\mathrm{W} / \mathrm{mK})$

\section{1) 3,02}

2) 3,34

4) 3,08

3) 3,03

Média $=3,12$

Variancia. $=0,02$

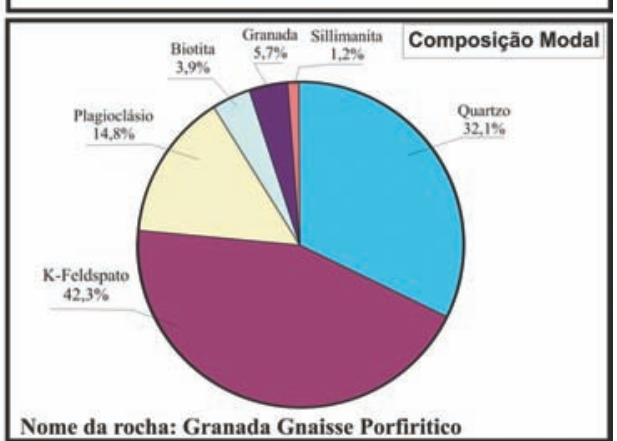

Figura 3 - Granito ornamental Branco Dallas e as medidas de condutividade térmica.

cal está relacionada à disposição dos pórfiros de K-feldspatos, circundando a matriz na parte central, funcionando assim como barreiras dificultando a condução do calor, Figura 4. A avaliação microscópica mostrou ainda que é na matriz da rocha que se observa importantes processos de alteração dos minerais, com a ênfase a saussuritização e muscovitização de cristais de plagioclásios, e ainda cloritização de cristais de biotita.

\section{Juparaíba (A36)}

A amostra é de uma rocha holocristalina, equigranular e textura gnáissica que apresenta duas regiões com composições mineralógicas similares, mas com variações modais distintas, uma hololeucocrática ( $<5,0 \%$ de minerais máficos), e outra leucocrática (>10,0\% de máficos). A porção hololeucocrática é 

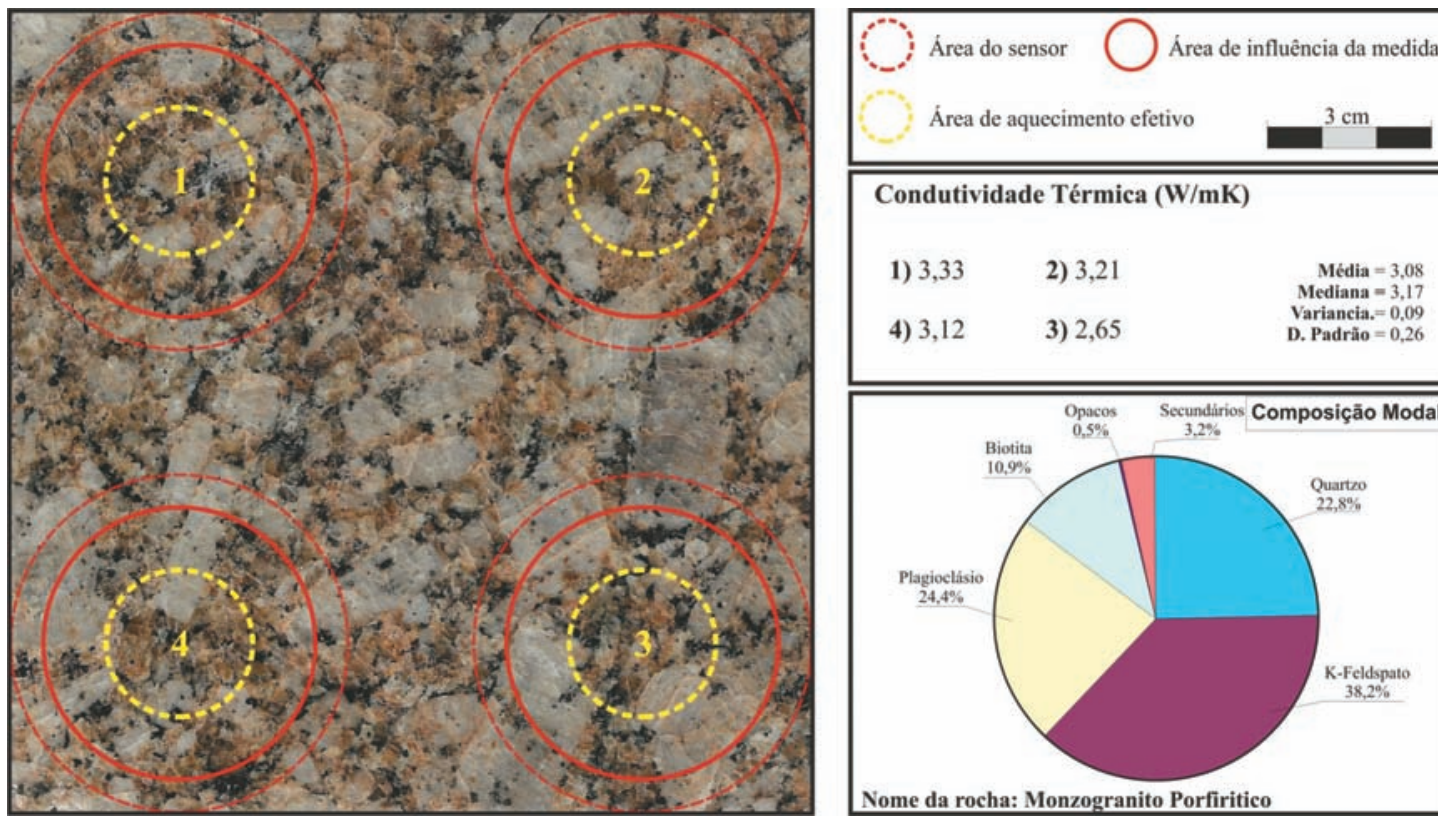

Condutividade Térmica $(\mathrm{W} / \mathrm{mK})$

$\begin{array}{llr}\text { 1) } 3,33 & \text { 2) } 3,21 & \begin{array}{r}\text { Media }=3,08 \\ \text { Mediana }=3,17 \\ \text { Variancia }=0.09 \\ \text { D. Padräo }=0,26\end{array} \\ \text { 4) } 3,12 & \text { 3) } 2,65 & \end{array}$

Figura 4 - Granito ornamental Dourado Carioca e as medidas de condutividade térmica.
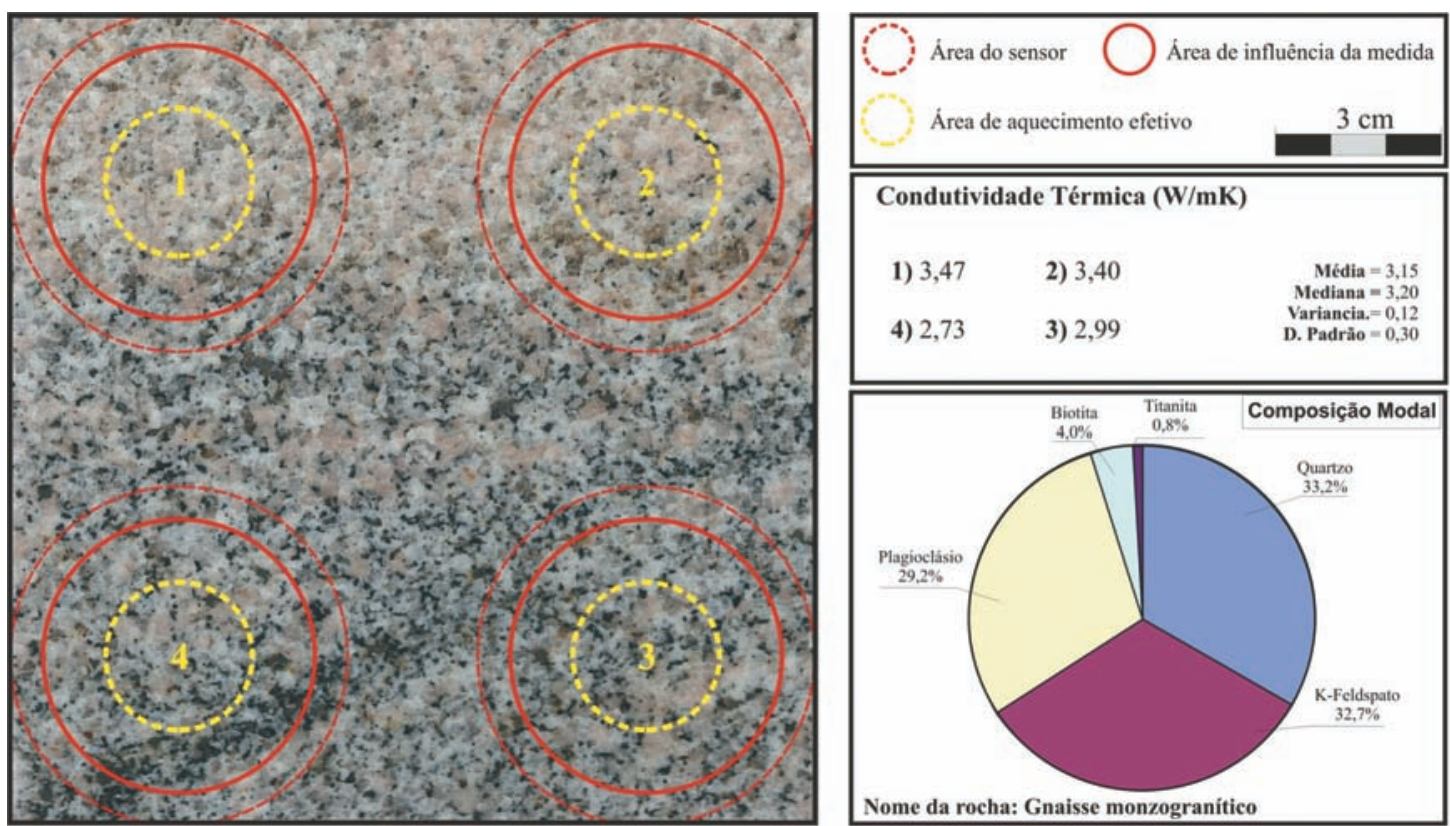

Condutividade Térmica $(\mathrm{W} / \mathrm{mK})$

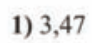

2) 3,40

Média $=3,15$

4) 2,73

3) 2,99

$\begin{aligned} \text { Mediana } & =3,20 \\ \text { Variancia. }=0,12 & \end{aligned}$

4) 2,73 D. Padräo $=0,30$

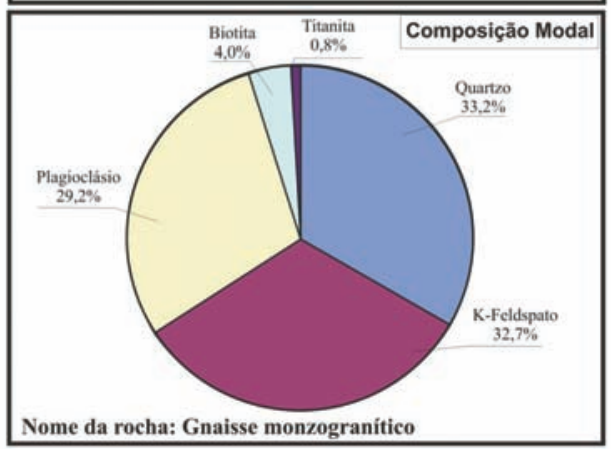

Figura 5 - Granito ornamental Juparaíba e as medidas de condutividade térmica.

constituída por quartzo $(33,2 \%)$ K-felsdpato $(32,7 \%)$, plagioclásio $(29,2 \%)$, biotita $(4 \%)$ e outros (minerais secundários $0,8 \%$ ). Já para porção mais enriquecida em máficos a mineralogia é constituída por quartzo (28,1\%), K-feldspato (29,8\%), plagioclásio $(27,7 \%)$, biotita $(11,9 \%)$ e outros (minerais secundários, opacos, titanita-2,5\%). A contagem modal das duas lâminas delgadas dessa amostra dá uma composição média de um gnaisse monzogranítico.

As quatro regiões de medida mostram valores de 3,47, 3,40, 2,99 e 2,73 W/mK, respectivamente (Fig. 5). As duas primeiras medidas de condutividade térmica foram realizadas na porção superior da amostra onde a percentagem de máficos não ultra- 
passa $5 \%$, apresentando aí os valores mais elevados de condutividade térmica (3,47 e 3,40 W/mK). Já as medidas "3" e "4", onde a percentagem de máficos chega a atingir $12 \%$, mostram diminuição considerável nos valores da condutividade térmica (2,99 e 2,73 W/mK), mostrando a influência do comportamento dos máficos atuando de forma a prejudicar a condução do calor, Figura 5. 0 valor médio da condutividade para esta amostra fica em $3,15 \pm 0,30 \mathrm{~W} / \mathrm{mK}$.

\section{ASPECTOS MICROSCÓPICOS}

Composicionalmente, as rochas estudadas (93 amostras) apresentam-se em sua maioria (aproximadamente 70\%) como monzogranitos, sienogranitos e granodioritos. Foram ainda avaliadas amostras de outros litotipos como: quartzo monzonitos, gabros, dioritos, quartzo sienitos, sienitos etc.

Moores \& Twiss (1995) propõem um intervalo médio de condutividade térmica para litotipos constituintes da crosta terrestre da ordem de 2,0 a 3,0 W/mK. Numa avaliação geral, o conjunto das amostras mostrou um intervalo de condutividade térmica que variou de $1,67 \mathrm{~W} / \mathrm{mK}$, valor médio obtido em um granito ornamental de composição sienítica, a 3,93 W/mK, média obtida em um granito ornamental (um gnaisse) de composição tonalítica, com média geral de 2,84 $\pm 0,49 \mathrm{~W} / \mathrm{mK}$, estando a média desta pesquisa dentro da faixa sugerida. A Tabela 2 contém todas as amostras estudadas com os dados relativos a mineralogia, textura, aos valores de condutividade térmica, hierarquizados em sentido crescente, a nomenclatura modal/petrográfica, e, para 0 caso das amostras de granitos ornamentais, seu nome fantasia/comercial.

\section{DISCUSSÃO DOS DADOS MICROSCÓPICOS}

Com 0 objetivo de se entender 0 efeito da mineralogia sobre a condutividade térmica, foram confeccionados gráficos de correlação linear (mineralogia vs. condutividade térmica) com todo o conjunto de amostras. No geral observou-se que há uma relação de aumento da condutividade térmica em função do aumento da percentagem de quartzo, mostrando que rochas mais ricas neste mineral possuem, no geral, valores maiores de condutividade térmica, como verificado na Figura 6A. Esta relação fica ainda mais evidente quando são comparadas as amostras com menos de $20 \%$ e mais de $20 \%$ de quartzo, onde é possível observar comportamentos bem distintos. 0 conjunto com mais de $20 \%$ de quartzo mostra em sua grande maioria valores de condutividade térmica que variam acima de $2,5 \mathrm{~W} / \mathrm{mK}$, já o conjunto com menos de $20 \%$ apresenta valores abaixo de 2,5 W/mK (Fig. 6A). Notadamente para as médias entre os intervalos de 0-5, 5-10, $10-15,15-20,20-25,25-30,30-35$ e $35-40 \%$ de quartzo a correlação com a condutividade térmica é muito boa, mostrando assim a importância deste mineral no controle deste parâmetro (Fig. 6B).

A relação dos feldspatos (K-feldspato e plagioclásio) com a condutividade térmica não evidenciou correlação alguma, mostrando uma dispersão dos dados (Figs. 6C e D). Por outro lado, os minerais máficos apresentam um comportamento oposto ao do quartzo, ou seja, quanto maior a percentagem de máficos menor a condutividade térmica da rocha (Fig. 6E). Por fim, para as médias dos intervalos de 0-5, 5-10, 10-15, 15-20, 20-25, 25-30, 30-35, 35-40, 40-45 e >45\% de máficos a correlação também é excelente e demonstra sua influência sobre a condutividade térmica (Fig. 6F). No que diz respeito aos máficos, dois fatores principais estariam influenciando os resultados obtidos. 0 primeiro seria que a um aumento de máficos associa-se uma diminuição relativa no conteúdo em quartzo na rocha, e o segundo seria 0 aumento da percentagem de filossilicatos, em especial micas (biotita e muscovita), minerais que no geral apresentam valores de condutividade térmica $<3,0$ W/mK (Horai, 1971; Cermak \& Rybach, 1982). Estes dois fatores potencializam uma diminuição da condutividade térmica.

Numa segunda abordagem as diferentes amostras estudadas foram separadas com base em seus aspectos texturais para se avaliar qual a influência do tamanho dos grãos minerais sobre 0 parâmetro condutividade térmica. Dessa forma, foram definidos dois grupos principais: amostras de textura fina/média e grossa/porfirítica. Para o caso do quartzo as amostras com textura grossa/porfirítica mostraram maior fator de correlação, quando comparados com as de textura fina/média (Figs. 7A e B). Quanto aos feldspatos (K-feldspato e plagioclásio), da mesma forma que no caso anterior (mineralogia vs. condutividade), os dados também não mostram boas correlações, observando-se uma forte dispersão para os dois grupos texturais (Figs. 7C, D, E e F). Por outro lado, para os máficos, os dois tipos texturais mostraram correlações negativas, entretanto, com fator de correlação menor do que os obtidos em relação ao quartzo (Figs. $7 \mathrm{G} \mathrm{e} \mathrm{H}$ ).

Quando são analisados os dois conjuntos texturais, apenas para 0 grupo de amostras que apresentam valores modais de quartzo acima de $20 \%$, o conjunto de dados estatisticamente mais representativo, observa-se que os litotipos de texturas grossas/porfiríticas (Fig. 8A), apresentam também uma correlação de aumento da condutividade com 0 aumento da porcentagem de quartzo, mas com fator de correlação relativamente baixo, enquanto os litotipos de texturas finas/médias mostram comportamento de dispersão (Fig. 8B), mas sempre com valores de condutividade superiores a 2,5 W/mK. Para os feldspatos (K-feldspato + plagioclásio) 0 comportamento das amostras é ainda de dispersão, quer seja para os litotipos finos/médios ou 
Tabela 2 - Composições modais, nomenclatura petrográfica e comercial e valores de condutividade térmica para as amostras estudadas.

\begin{tabular}{|c|c|c|c|c|c|c|c|c|c|}
\hline Amostra & $Q z$ & $\mathrm{~K}-\mathrm{F}$ & $\mathrm{Pl}$ & $M$ & $\bar{\Sigma}$ & $\bar{\lambda}$ & Nome petrográfico & Textura & Nome comercial \\
\hline A53 & 6,0 & 57,2 & 21,3 & 15,5 & 100,0 & 1,67 & Quartzo sienito & $\mathrm{G} / \mathrm{P}$ & Blue Pearl \\
\hline LG-15C & 15,5 & 6,3 & 42,2 & 36,0 & 100,0 & 1,79 & Quartzo diorito & F/M & \\
\hline $\mathrm{A} 02$ & 7,5 & 36,1 & 26,0 & 30,5 & 100,0 & 1,87 & Quartzo monzonito & F/M & Ocre Itabira \\
\hline $1-29$ & 0,8 & 0,0 & 62,0 & 37,2 & 100,0 & 1,89 & Gabro & F/M & \\
\hline A23 & 0,0 & 0,3 & 49,0 & 50,7 & 100,0 & 1,93 & Gabro & F/M & Preto Ônix \\
\hline A46 & 3,0 & 50,0 & 26,4 & 20,6 & 100,0 & 2,00 & Sienito & F/M & Branco Ártico \\
\hline $1-08$ & 1,2 & 0,6 & 54,4 & 43,8 & 100,0 & 2,01 & Gabro & F/M & \\
\hline LG-206 & 3,2 & 0,0 & 19,7 & 77,1 & 100,0 & 2,03 & Norito & F/M & \\
\hline A11 & 0,0 & 0,6 & 58,0 & 41,4 & 100,0 & 2,08 & Gabro & F/M & Preto Absoluto \\
\hline A19 & 13,1 & 6,0 & 77,2 & 3,7 & 100,0 & 2,08 & Quartzo diorito & F/M & Ás de Paus \\
\hline CR-108 & 18,2 & 9,1 & 46,3 & 26,4 & 100,0 & 2,18 & Granodiorito & F/M & \\
\hline A54 & 10,0 & 7,2 & 40,0 & 42,8 & 100,0 & 2,24 & Quartzo monzogabro & F/M & Preto São Marcos \\
\hline A52 & 6,5 & 43,6 & 12,2 & 37,7 & 100,0 & 2,24 & Quartzo sienito & $\mathrm{G} / \mathrm{P}$ & Azul Bahia \\
\hline CR-105 & 19,2 & 19,2 & 33,9 & 27,7 & 100,0 & 2,29 & Monzogranito & $\mathrm{G} / \mathrm{P}$ & \\
\hline A26 & 10,8 & 59,1 & 8,0 & 22,1 & 100,0 & 2,29 & Quartzo sienito & $\mathrm{G} / \mathrm{P}$ & Lilás Imperial \\
\hline U-118 & 15,6 & 59,4 & 19,5 & 5,5 & 100,0 & 2,35 & Quartzo sienito & $\mathrm{G} / \mathrm{P}$ & \\
\hline CR-02 & 0,0 & 55,0 & 5,2 & 35,9 & 100,0 & 2,42 & Álcali feldspato sienito & F/M & \\
\hline P-06 & 1,3 & 0,0 & 56,7 & 42,0 & 100,0 & 2,43 & Gabro & F/M & \\
\hline A50 & 4,8 & 58,0 & 3,8 & 33,4 & 100,0 & 2,43 & Quartzo álcali feldspato sienito & $\mathrm{G} / \mathrm{P}$ & Café Bahia \\
\hline A05 & 7,7 & 28,7 & 33,6 & 30,0 & 100,0 & 2,44 & Quartzo monzonito & $\mathrm{G} / \mathrm{P}$ & Verde Ubatuba \\
\hline CR-03 & 0,0 & 50,3 & 11,3 & 34,0 & 100,0 & 2,48 & Sienito & F/M & \\
\hline CR-104 & 22,7 & 22,7 & 21,7 & 32,9 & 100,0 & 2,52 & Monzogranito & $\mathrm{G} / \mathrm{P}$ & \\
\hline CR-38 & 19,3 & 21,6 & 32,4 & 26,7 & 100,0 & 2,55 & Monzogranito & $\mathrm{G} / \mathrm{P}$ & \\
\hline LG 15a & 15,0 & 25,9 & 47,2 & 11,9 & 100,0 & 2,56 & Quartzo monzodiorito & $\mathrm{G} / \mathrm{P}$ & \\
\hline CR-73 & 21,8 & 26,4 & 34,3 & 17,5 & 100,0 & 2,57 & Monzogranito & $\mathrm{G} / \mathrm{P}$ & \\
\hline CR-08 & 28,8 & 31,5 & 20,7 & 19,0 & 100,0 & 2,57 & Monzogranito & F/M & \\
\hline A47 & 19,9 & 40,3 & 25,4 & 14,4 & 100,0 & 2,58 & Monzogranito & $\mathrm{G} / \mathrm{P}$ & Azul Patara \\
\hline MA-112 & 26,5 & 43,8 & 25,4 & 4,3 & 100,0 & 2,59 & Monzogranito & F/M & \\
\hline A09 & 16,6 & 47,8 & 25,4 & 10,2 & 100,0 & 2,59 & Quartzo sienito & F/M & Cinza Real \\
\hline $\mathrm{A} 01$ & 32,7 & 5,8 & 48,0 & 13,5 & 100,0 & 2,61 & Tonalito & F/M & Cinza Elite \\
\hline CR-09b & 35,8 & 33,4 & 27,0 & 3,8 & 100,0 & 2,61 & Monzogranito & F/M & \\
\hline CR-17 & 29,1 & 12,0 & 37,2 & 21,7 & 100,0 & 2,66 & Granodiorito & $\mathrm{G} / \mathrm{P}$ & \\
\hline MA-21 & 26,4 & 34,7 & 30,5 & 8,4 & 100,0 & 2,67 & Monzogranito & F/M & \\
\hline A38 & 22,3 & 21,6 & 33,1 & 23,0 & 100,0 & 2,68 & Monzogranito & $\mathrm{G} / \mathrm{P}$ & Cinza Corumbazinho \\
\hline $\mathrm{A} 27$ & 27,7 & 38,4 & 23,3 & 10,6 & 100,0 & 2,68 & Gnaisse monzogranítico & F/M & Cinza Wave \\
\hline A35 & 28,9 & 20,2 & 45,3 & 5,6 & 100,0 & 2,69 & Granodiorito & F/M & Branco Jabre \\
\hline CR-56 & 35,0 & 22,6 & 18,3 & 24,1 & 100,0 & 2,72 & Monzogranito & F/M & \\
\hline A21 & 21,8 & 40,5 & 25,1 & 12,6 & 100,0 & 2,75 & Monzogranito & F/M & Cinza Andorinha \\
\hline $\mathrm{A} 12$ & 22,9 & 47,6 & 25,4 & 4,1 & 100,0 & 2,76 & Sienogranito & F/M & Branco Pérola \\
\hline CR-67 & 24,6 & 36,0 & 16,0 & 23,4 & 100,0 & 2,77 & Sienogranito & $\mathrm{G} / \mathrm{P}$ & \\
\hline CR-23 & 24,0 & 37,4 & 24,6 & 14,0 & 100,0 & 2,79 & Monzogranito & F/M & \\
\hline CR-37 & 32,0 & 13,9 & 28,7 & 25,4 & 100,0 & 2,80 & Granodiorito & F/M & \\
\hline CR-18 & 28,6 & 33,4 & 28,5 & 9,5 & 100,0 & 2,80 & Monzogranito & F/M & \\
\hline CR-100 & 37,0 & 20,1 & 31,9 & 11,0 & 100,0 & 2,86 & Monzogranito & F/M & \\
\hline CR-102 & 21,5 & 28,4 & 37,3 & 12,8 & 100,0 & 2,86 & Monzogranito & F/M & \\
\hline A42 & 28,3 & 34,2 & 31,7 & 5,8 & 100,0 & 2,87 & Monzogranito & $\mathrm{G} / \mathrm{P}$ & Verde Top \\
\hline CABO & 26,2 & 49,0 & 21,0 & 3,8 & 100,0 & 2,87 & Sienogranito & F/M & \\
\hline A33 & 32,2 & 29,6 & 25,7 & 12,5 & 100,0 & 2,90 & Monzogranito & $\mathrm{F} / \mathrm{M}$ & Amarelo Minas \\
\hline
\end{tabular}


Tabela 2 - (Continuação).

\begin{tabular}{|c|c|c|c|c|c|c|c|c|c|}
\hline Amostra & $\mathrm{Qz}$ & $\mathrm{K}-\mathrm{F}$ & $\mathrm{Pl}$ & $M$ & $\Sigma$ & $\lambda$ & Nome petrográfico & Textura & Nome comercial \\
\hline A20 & 33,1 & 54,1 & 8,9 & 3,9 & 100,0 & 2,92 & Sienogranito & $\mathrm{G} / \mathrm{P}$ & Meruoca Clássico \\
\hline A06 & 26,1 & 3,4 & 52,7 & 17,8 & 100,0 & 2,96 & Tonalito & $\mathrm{G} / \mathrm{P}$ & Cinza Brunet \\
\hline CR-54A & 34,1 & 13,2 & 27,7 & 25,0 & 100,0 & 2,96 & Granodiorito & F/M & \\
\hline A24 & 30,2 & 29,9 & 32,9 & 7,0 & 100,0 & 2,96 & Monzogranito & $\mathrm{F} / \mathrm{M}$ & Verde Caravelas \\
\hline A08 & 28,9 & 54,7 & 11,6 & 4,8 & 100,0 & 2,98 & Sienogranito & F/M & Juparaná Gold \\
\hline CR-41 & 19,6 & 35,3 & 22,8 & 22,3 & 100,0 & 2,99 & Monzogranito & F/M & \\
\hline CR-106 & 35,9 & 15,7 & 28,8 & 19,6 & 100,0 & 3,04 & Monzogranito & $\mathrm{G} / \mathrm{P}$ & \\
\hline CR-98 & 40,7 & 22,2 & 23,2 & 13,9 & 100,0 & 3,05 & Monzogranito & F/M & \\
\hline CR-25 & 28,5 & 10,1 & 37,6 & 23,8 & 100,0 & 3,07 & Granodiorito & F/M & \\
\hline $\mathrm{A} 07$ & 22,8 & 38,2 & 24,4 & 14,6 & 100,0 & 3,08 & Monzogranito & $\mathrm{G} / \mathrm{P}$ & Dourado Carioca \\
\hline A34 & 26,1 & 34,2 & 25,4 & 14,3 & 100,0 & 3,09 & Monzogranito & F/M & Rosa Capri \\
\hline $\mathrm{A} 03$ & 22,3 & 35,7 & 18,3 & 23,7 & 100,0 & 3,09 & Sienogranito & $\mathrm{G} / \mathrm{P}$ & Amarelo Laranjeira \\
\hline A49 & 29,0 & 43,9 & 22,1 & 5,0 & 100,0 & 3,09 & Sienogranito & F/M & Amarelo Maracujá \\
\hline CR-27A & 20,9 & 28,7 & 32,4 & 18,0 & 100,0 & 3,10 & Monzogranito & F/M & \\
\hline CR-79 & 25,1 & 39,8 & 16,9 & 18,2 & 100,0 & 3,10 & Sienogranito & F/M & \\
\hline A37 & 24,2 & 39,2 & 33,0 & 3,6 & 100,0 & 3,11 & Monzogranito & $\mathrm{F} / \mathrm{M}$ & Amarelo Capri \\
\hline CR-19 & 35,8 & 10,6 & 37,9 & 15,7 & 100,0 & 3,12 & Granodiorito & F/M & \\
\hline CR-81 & 33,8 & 21,3 & 25,9 & 19,0 & 100,0 & 3,12 & Monzogranito & F/M & \\
\hline CR-87 & 37,0 & 24,1 & 23,8 & 15,1 & 100,0 & 3,12 & Monzogranito & $\mathrm{G} / \mathrm{P}$ & \\
\hline A40 & 17,4 & 28,0 & 38,0 & 16,6 & 100,0 & 3,12 & Gnaisse monzogranítico & $\mathrm{G} / \mathrm{P}$ & Casablanca \\
\hline A04 & 32,1 & 42,3 & 14,8 & 10,8 & 100,0 & 3,12 & Gnaisse sienogranítico & $\mathrm{G} / \mathrm{P}$ & Branco Dallas \\
\hline $\mathrm{A} 17$ & 32,6 & 22,7 & 34,4 & 10,3 & 100,0 & 3,14 & Monzogranito & F/M & Vermelho Imperial \\
\hline CR-63 & 35,4 & 24,0 & 29,9 & 10,7 & 100,0 & 3,14 & Monzogranito & $\mathrm{G} / \mathrm{P}$ & \\
\hline A36 & 33,2 & 32,7 & 29,2 & 4,9 & 100,0 & 3,15 & Gnaisse monzogranítico & F/M & Juparaíba \\
\hline CR-107 & 33,3 & 22,5 & 26,3 & 17,9 & 100,0 & 3,16 & Monzogranito & $\mathrm{G} / \mathrm{P}$ & \\
\hline A43 & 18,0 & 55,0 & 12,0 & 15,0 & 100,0 & 3,17 & Sienogranito & $\mathrm{G} / \mathrm{P}$ & Red Dragon \\
\hline A28 & 27,5 & 56,1 & 8,3 & 8,1 & 100,0 & 3,18 & Sienogranito & F/M & Amarelo Icaraí \\
\hline A41 & 27,3 & 33,0 & 24,1 & 15,6 & 100,0 & 3,20 & Monzogranito & $\mathrm{G} / \mathrm{P}$ & Caramelo Bahia \\
\hline A10 & 32,1 & 36,7 & 24,7 & 6,5 & 100,0 & 3,23 & Monzogranito & $\mathrm{G} / \mathrm{P}$ & Rosa Iracema \\
\hline A32 & 24,6 & 56,6 & 16,6 & 2,2 & 100,0 & 3,26 & Sienogranito & F/M & Branco Aqualux \\
\hline A48 & 34,3 & 44,1 & 17,2 & 4,4 & 100,0 & 3,29 & Monzogranito & $\mathrm{G} / \mathrm{P}$ & Juparaná Montiel \\
\hline A13 & 27,6 & 15,1 & 47,5 & 9,8 & 100,0 & 3,32 & Sienogranito & F/M & Branco Cristal \\
\hline CR-301 & 35,2 & 35,8 & 26,4 & 2,6 & 100,0 & 3,32 & Monzogranito & F/M & \\
\hline A18 & 26,9 & 39,5 & 31,4 & 2,2 & 100,0 & 3,33 & Monzogranito & F/M & Branco Savana \\
\hline A31 & 37,8 & 48,4 & 5,4 & 8,4 & 100,0 & 3,33 & Sienogranito & $\mathrm{G} / \mathrm{P}$ & Verde Ceará \\
\hline A44 & 29,1 & 33,1 & 29,0 & 8,8 & 100,0 & 3,38 & Monzogranito & F/M & Verde Oceano \\
\hline CR-300a & 26,9 & 24,0 & 43,0 & 6,1 & 100,0 & 3,43 & Monzogranito & F/M & \\
\hline A22 & 34,2 & 50,1 & 6,5 & 9,2 & 100,0 & 3,50 & Álcali feldspato granito & $\mathrm{G} / \mathrm{P}$ & Amarelo St. Cecília \\
\hline A16 & 24,8 & 27,0 & 37,7 & 10,5 & 100,0 & 3,52 & Monzogranito & F/M & Vermelho Flores \\
\hline A51 & 28,0 & 37,0 & 28,0 & 7,0 & 100,0 & 3,58 & Monzogranito & F/M & Vino Bahia \\
\hline A29 & 32,7 & 46,2 & 16,7 & 4,4 & 100,0 & 3,61 & Sienogranito & $\mathrm{G} / \mathrm{P}$ & Vermelho Brasília \\
\hline A14 & 33,3 & 39,1 & 16,5 & 11,1 & 100,0 & 3,72 & Sienogranito & $\mathrm{G} / \mathrm{P}$ & Capão Bonito \\
\hline A30 & 31,1 & 45,6 & 16,7 & 6,6 & 100,0 & 3,72 & Sienogranito & $\mathrm{G} / \mathrm{P}$ & Verde Meruoca \\
\hline A55 & 29,8 & 41,9 & 23,4 & 4,9 & 100,0 & 3,88 & Sienogranito & $\mathrm{G} / \mathrm{P}$ & Chocolate Brasil \\
\hline A39 & 33,3 & 2,2 & 14,4 & 50,1 & 100,0 & 3,93 & Gnaisse tonalítico & $\mathrm{G} / \mathrm{P}$ & Preto Indiano \\
\hline
\end{tabular}

Obs.: Qz (Quartzo), K-F (K-feldspato), Pl (plagioclásio), M (máficos: piroxênios, anfibólios, micas, titanita, minerais opacos etc.), $\Sigma$ (somatório modal), $\lambda$ (condutividade térmica). 

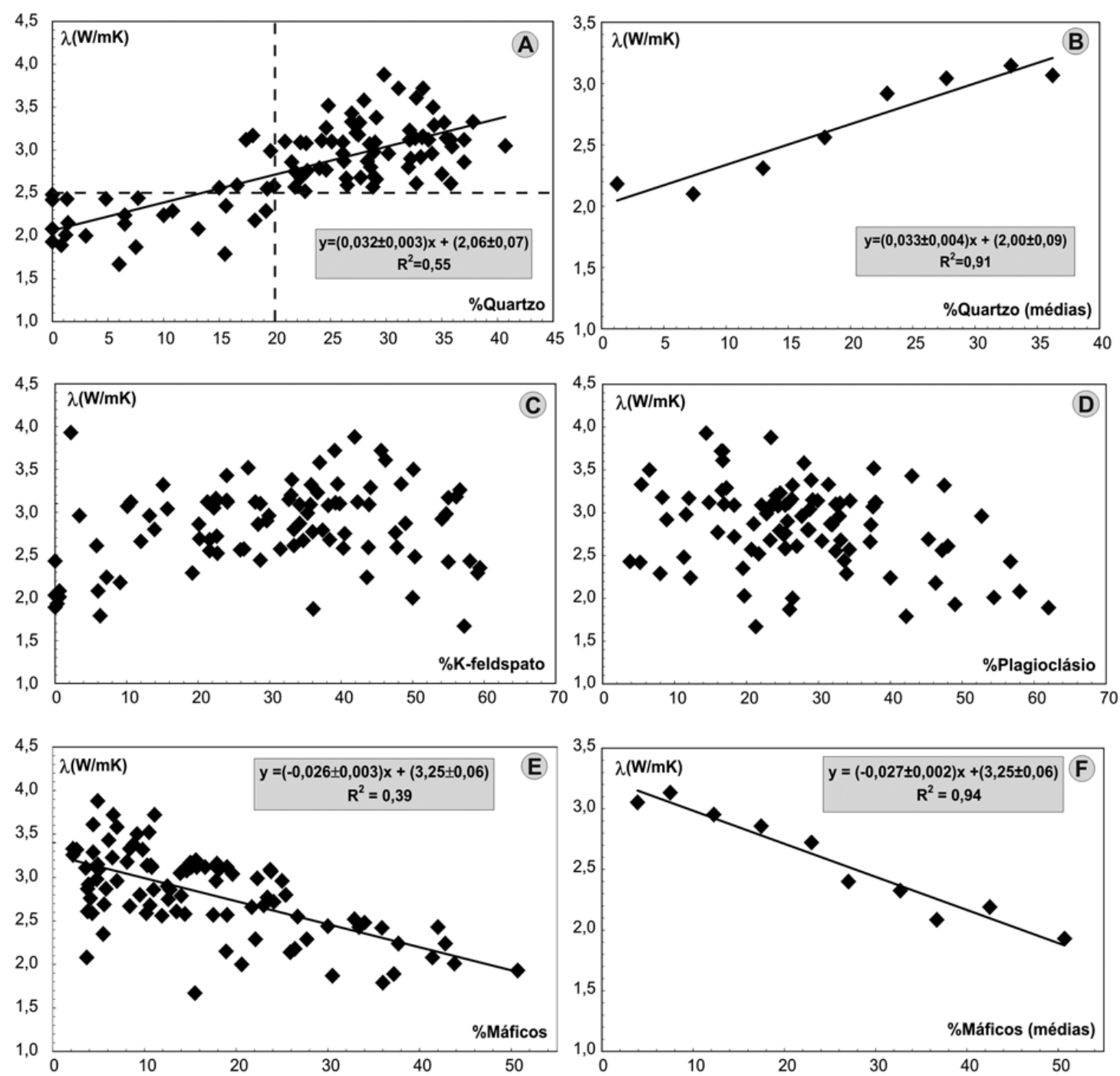

Figura 6 - Relação entre condutividade térmica e: porcentagem de quartzo (A), média da porcentagem de quartzo para os intervalos 0-5, 5-10, 10-15, 15-20, 20-25, 25-30, 30-35, 35-40\% (B), porcentagem de K-feldspato (C), porcentagem de plagioclásio (D), porcentagem de máficos (E) e média da porcentagem de máficos para os intervalos 0-5, 5-10, 10-15, 15-20, 20-25, 25-30, 30-35, 35-40, 40-45 e >45\% (F).

grossos/porfiríticos, assim como observado nos casos anteriores. Para os minerais máficos ocorre uma correlação negativa para os tipos de textura grossa/porfirítica, e uma dispersão para as de textura fina/média (Figs. 8C e D).

\section{CORRELAÇÃO COM OS LITOTIPOS}

0 conjunto de amostras estudado foi agrupado com base nas suas composições modais, quando plotadas no diagrama modal QAP de Streckeisen (1976), e realizada uma discussão envolvendo "litotipos modais vs. condutividade térmica". Neste contexto foram definidos então quatro grupos/conjuntos de litotipos (Tabs. 3 e 4, Fig. 9):
(1) Rochas Graníticas (álcali feldspato granito, sienogranito, monzogranito, granodiorito e tonalito);

(2) Rochas Sienitos (quartzo álcali feldspato sienito, quartzo sienito, álcali feldspato sienito e sienito);

(3) Rochas Monzonitos (quartzo monzonito e monzonitos);

(4) Rochas Intermediárias/Máficas (quartzo monzodiorito/monzogabro, quartzo diorito/gabro e diorito/gabro/norito).

0 conjunto 1 (litotipos com mais de $20 \%$ de quartzo), mostrou os maiores valores médios de condutividade térmica (Tab. 3), ficando evidente ainda uma tendência de diminuição, 

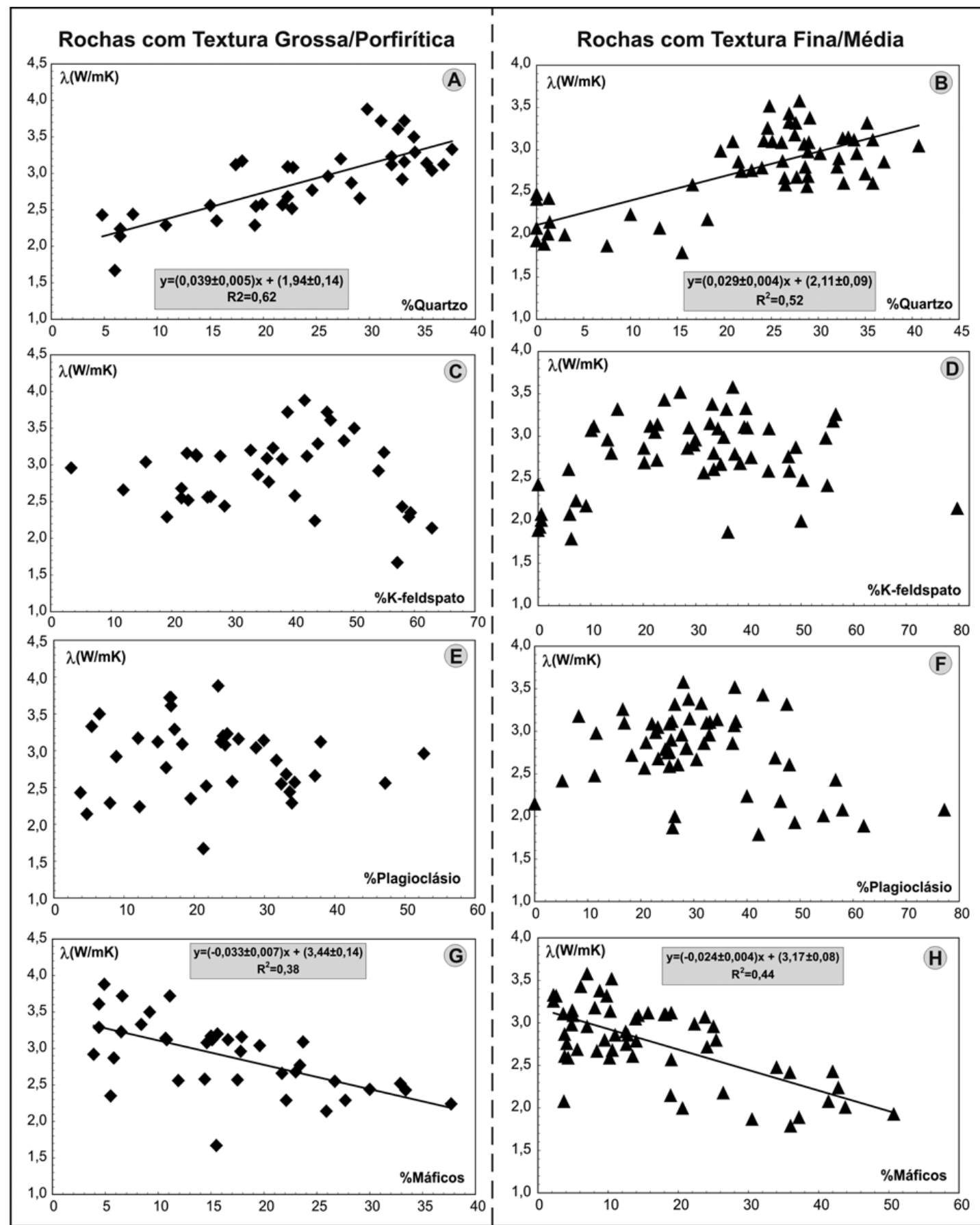

Figura 7 - Relação entre condutividade térmica e: porcentagem de quartzo (A) e (B), porcentagem de K-feldspato (C) e (D), porcentagem de plagioclásio $(E)$ e (F), e porcentagem de máficos $(G)$ e $(H)$, para as rochas com texturas grossa/porfirítica e fina/média.

dentro deste conjunto, no sentido dos álcali feldspatos granitos para os tonalitos, (usualmente há um aumento de minerais máficos neste sentido), corroborando assim com os dados de correlação entre condutividade térmica e mineralogia discutidos nos itens anteriores (Tab. 3). A média das 72 amostras deste conjunto (rochas graníticas) foi de 3,13 $\pm 0,27 \mathrm{~W} / \mathrm{mK}$ (Tab. 3), portanto, dentro da média sugerida por diversos autores tais como, Schön (1996), Clauser \& Huenges (1995), entre outros. 


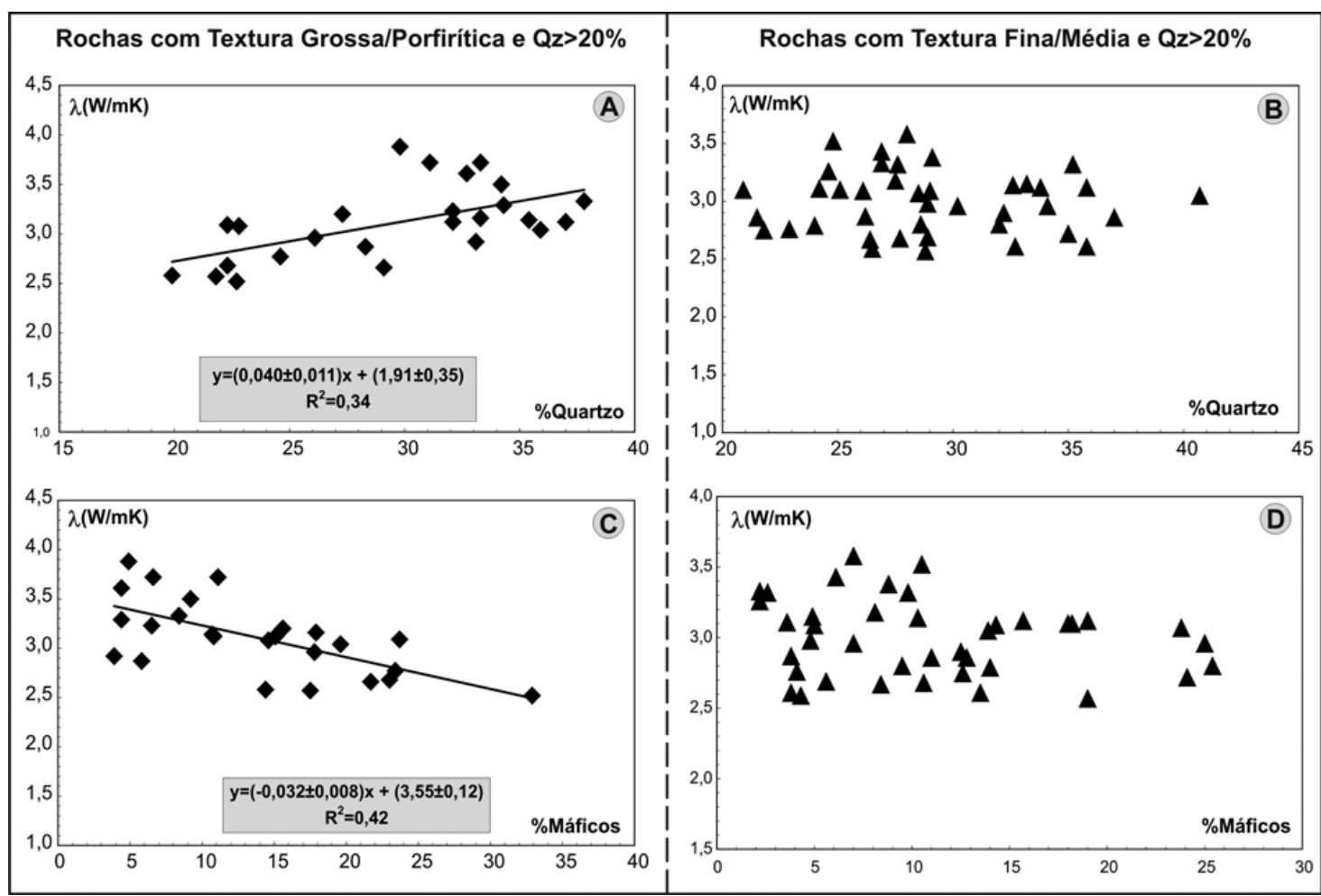

Figura 8 - Relação entre condutividade térmica e: porcentagem de quartzo (A) e (B), porcentagem de máficos (C) e (D), para as rochas com texturas grossa/porfirítica e fina/média com valores modais de quartzo $>20 \%$.

Tabela 3 - Rochas graníticas e respectivas médias de condutividade térmica, e número de amostras estudadas.

\begin{tabular}{|c|c|c|c|c|c|}
\hline & AFG & Sienogranito & Monzogranito & Granodiorito & Tonalito \\
\hline Cond. térmica & 3,5 & $3,22 \pm 0,33$ & $2,97 \pm 0,30$ & $2,78 \pm 0,32$ & $3,17 \pm 0,68$ \\
\hline $\mathrm{N}^{\circ}$ de amostras & 1 & 18 & 43 & 7 & 3 \\
\hline
\end{tabular}

Obs.: AFG (álcali feldspato granito).

Tabela 4 - Amostras com menos de $20 \%$ de quartzo e respectivas médias de condutividade térmica e número de amostras.

\begin{tabular}{|c|c|c|c|}
\hline & Sienitóides & Monzonitos & Conjunto 4 \\
\hline Cond. térmica & $2,27 \pm 0,28$ & $2,16 \pm 0,40$ & $2,10 \pm 0,24$ \\
\hline $\mathrm{N}^{\circ}$ de amostras & 9 & 2 & 10 \\
\hline
\end{tabular}

Obs.: Conjunto 4 (quartzo monzodiorito/monzogabro, quartzo diorito/gabro e diorito/gabro/norito).

Os conjuntos 2, 3 e 4 (amostras com menos de 20\% de quartzo), da mesma forma como verificado nas amostras com mais de $20 \%$ de quartzo, também mostram uma diminuição nos valores de condutividade térmica no sentido da esquerda para direita no diagrama QAP, onde os sienitos e monzonitos se mostraram mais susceptíveis a condução de calor que os litotipos de natureza intermediário/máficos (monzodiorito/monzogabro e diorito/gabro), conjunto 4 (Tab. 4). A média para estes três grupos ficou em torno de 2,18 $\pm 0,09 \mathrm{~W} / \mathrm{mK}$.

A relação entre percentagem de quartzo e a condutividade térmica fica ainda mais evidente quando são plotados os resultados modais no diagrama QAP (Fig. 9A). Verifica-se que aquelas amostras com condutividades térmicas inferiores a 2,5 W/mK possuem quase sempre percentagens inferiores a 20\% de quartzo. Aquelas com condutividades superiores a 2,5 W/mK sempre possuem percentagens maiores que $20 \%$, dividindo portanto 0 diagrama em duas regiões principais de condutividade térmica, aquelas com condutividades altas $(>2,5 \mathrm{~W} / \mathrm{mK}) \mathrm{com}$ percentagens sempre superiores a $20 \%$ de quartzo e aquelas com condutividades baixas $(<2,5 \mathrm{~W} / \mathrm{mK})$ sempre com percentagens inferiores a 20\% de quartzo, ratificando assim os dados de mineralogia anteriormente citados. 0 diagrama $\mathrm{Q}-\mathrm{A}+\mathrm{P}-\mathrm{M}$ (Fig. 9B) 


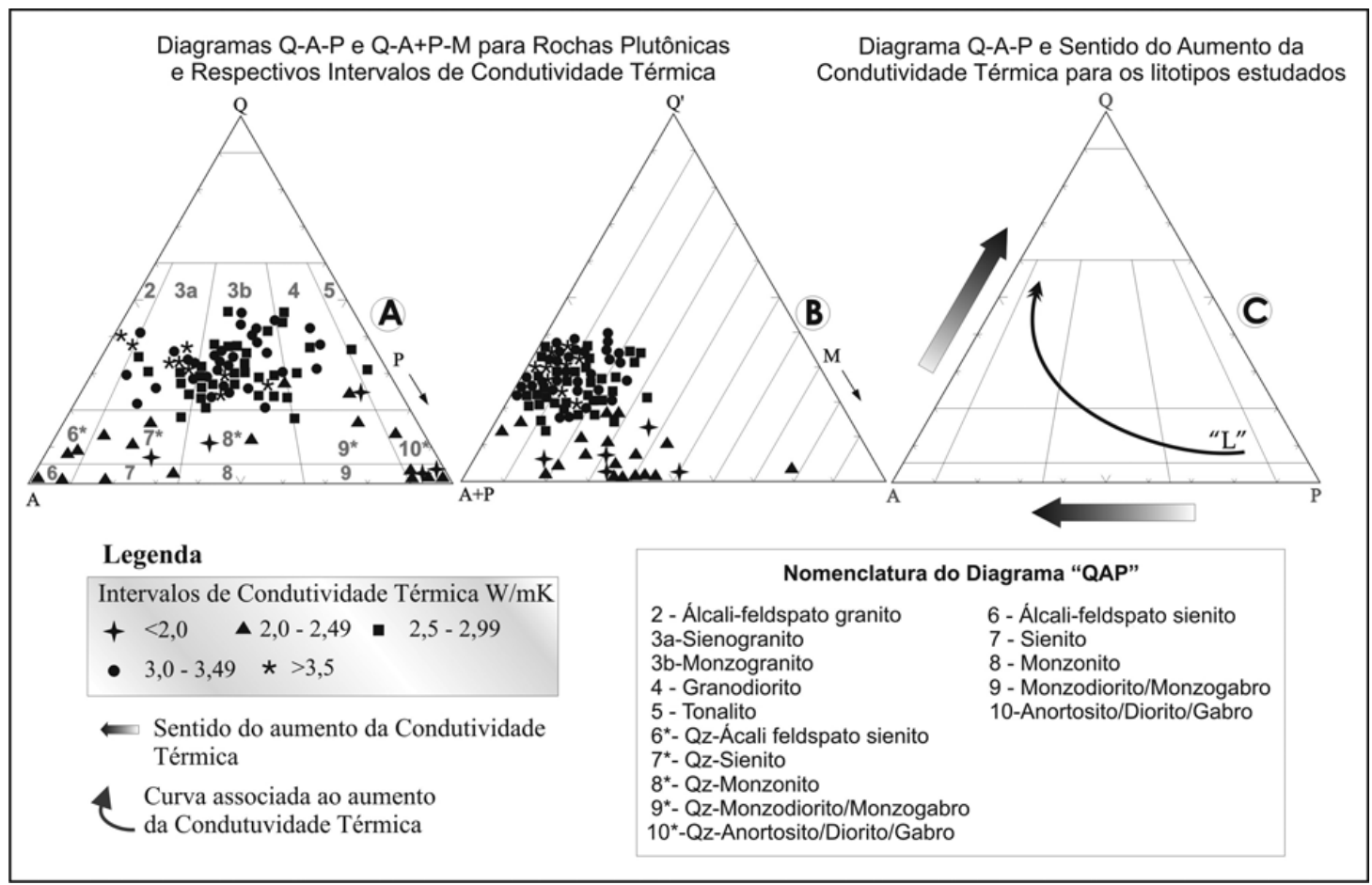

Figura 9 - "A" e "B" Conjunto de amostras no diagrama QAP (Streckeisen, 1976), e respectivo intervalo de condutividade térmica. "C" Sentido do aumento da condutividade térmica baseado nas interpretações dos gráficos.

confirma estes dados na medida em que mostra os litotipos com as mais altas condutividades ( $>3,5 \mathrm{~W} / \mathrm{mK})$, apresentando baixos valores de máficos, estes nunca ultrapassando $12 \%$. Os litotipos com condutividade térmica entre 3,0 e 3,49 W/mK mostram em grande parte percentagens de máficos até $20 \%$. Em contrapartida aqueles litotipos com mais de $20 \%$ de máficos apresentam quase sempre valores abaixo de $3,0 \mathrm{~W} / \mathrm{mK}$, com tendência de queda com 0 aumento destes.

0 comportamento da percentagem de quartzo ( $>20 \%$ ) ou da presença de máficos (>20\%) pode ser explicado estatisticamente através da Figura 10A, onde é possível notar que a partir da percentagem de $15 \%$ já ocorrem contatos maiores entre os minerais, 0 que não se observa (probabilidade muito pequena ou menor) nas percentagens de 1,5 e 10\%, por exemplo. Já para a percentagem correspondente a $20 \%$, os contatos entre os cristais já são bem mais pronunciados (probabilidade maior), sendo formados "canais" que funcionarão como facilitadores da condução do calor, no caso do quartzo, ou como barreiras no caso dos filossilicatos (biotitas, muscovitas etc.). Nos valores correspondentes a 25 e 30\%, por exemplo, os contatos já são muito abundantes (probabilidade muito maior). Em resumo, pode-se sugerir a existência de uma zona de controle de condutividade térmica que estaria localizada em torno de $20 \%$ de quartzo, correspondente a aproximadamente $2,5 \mathrm{~W} / \mathrm{mK}$.
Tão importante quanto a percentagem absoluta ou modal é a forma como encontra-se distribuída determinada fase mineral. As Figuras 10B e C demonstram bem tal problemática, onde é possível perceber que uma mesma percentagem mineral pode ocorrer concentrada em poucos cristais de tamanho grande ou em muitos cristais de tamanho pequeno. Especificamente para a condutividade térmica há um favorecimento da condução de caIor quando os cristais são bem desenvolvidos, justificando em algumas situações, por exemplo, no caso de rochas de textura grossa/porfirítica os valores médios superiores, (>10\%) aos encontrados nas de textura fina/média.

\section{CONSIDERAÇÕES FINAIS}

Os aspectos macroscópicos permitiram avaliar e correlacionar com bom grau de precisão os efeitos da mineralogia/composição modal (quartzo, plagioclásio, granada, demais máficos etc.) e da textura/estrutura na condutividade térmica, servindo assim como ferramenta preditiva para o comportamento da condutividade térmica no meio rochoso. Aspectos relativos ainda ao grau e tipo de alterações nas rochas (oxidação de minerais etc.), têm implicações nos valores de condutividade térmica, usualmente diminuídos (Figueiredo, 2006).

No que diz respeito aos aspectos mineralógicos/petrográficos, a partir do estudo de lâminas delgadas ao microscópio 

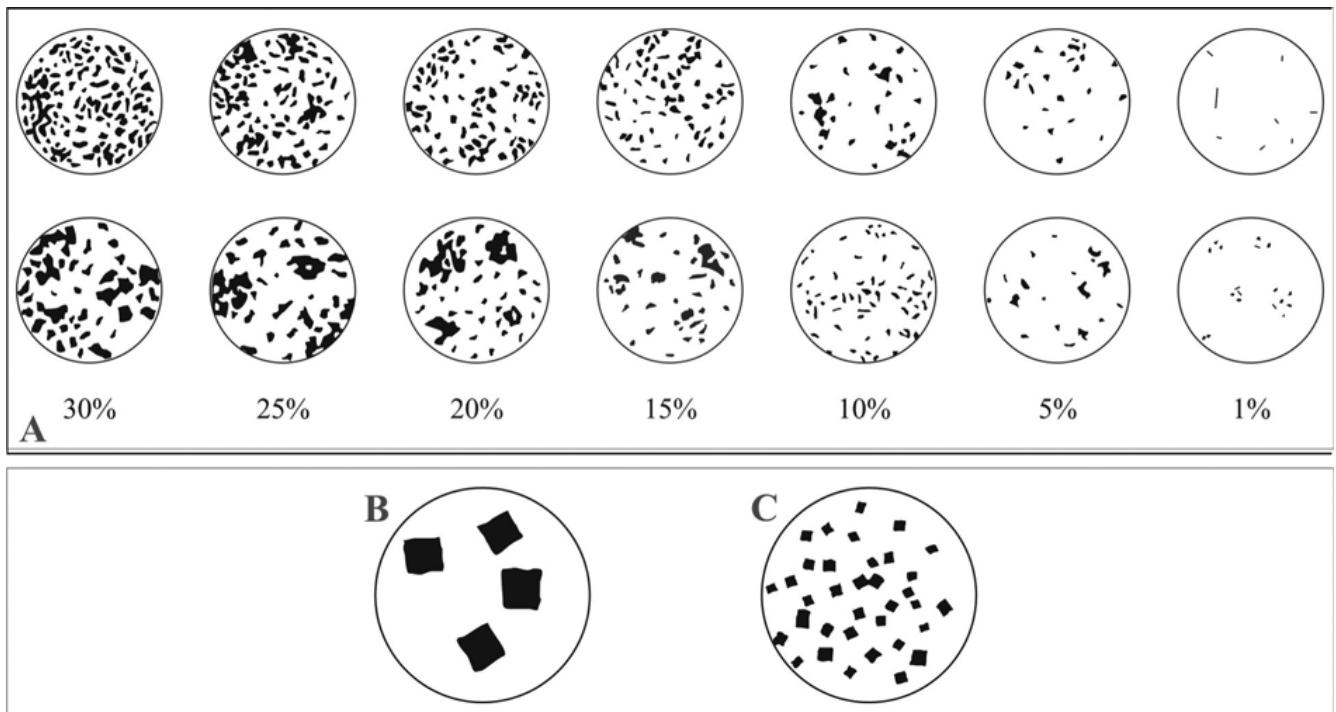

Figura 10 - Modificado de Best (1982). A) Percentagem mineral e suas probabilidades de contato entre grãos da mesma espécie (quartzo). B) Poucos cristais com grandes dimensões. C) Numerosos cristais com pequenas dimensões.

petrográfico, constata-se que 0 quartzo é o mineral que mostra as melhores correlações, sendo um fator importante e decisivo, e sua ausência, ou presença, implicarão em resultados muito diferenciados de condutividade térmica. Quando ausente, a nova fase dominante (feldspatos, máficos etc.) determinaram o comportamento da condução de calor, entretanto sempre com valores mais baixos quando comparados com os resultados obtidos com a presença do quartzo. Em todas as situações ficaram evidentes correlações positivas, onde ficou demonstrado a relação de alta condutividade em litotipos félsicos e baixas condutividades em litotipos intermediários a máficos. Ainda para ratificar este comportamento dominante verificou-se que litotipos com mais de $20 \%$ de quartzo apresentaram condutividade térmicas superiores a 2,5 W/mK. Este resultado, quando visualizado no diagrama QAP (Streckeisen, 1976), demonstra que as rochas granitóides (álcali feldspato granito, sienogranito, monzogranito, granodiorito e tonalito) tenderão a apresentar condutividades térmicas superiores às rochas com menos de $20 \%$ de quartzo (sienitóides, monzonitos, gabros, dioritos etc.).

Os resultados observados para os feldspatos (plagioclásio e K-feldspato) não são satisfatórios e mostram sempre uma dispersão. Os máficos, por fim, mostram um papel decisivo na diminuição da condutividade térmica, resultados confirmados ainda pelo diagrama QAP de Streckeisen (1976) e pelas avaliações macroscópicas.

Quanto aos aspectos texturais, nota-se uma melhor correlação para os litotipos de natureza grossa/porfirítica, mostrando em quase todos os casos melhores fatores de correlação quando comparadas com os tipos finos/médios. Verifica-se, ainda, que a relação do tamanho dos minerais e a forma como estão distribuídos é determinante no comportamento da condutividade térmica. Proporções com mais de $20 \%$ de quartzo e com textura porfirítica tendem a favorecer a condução do calor quando comparadas com aquelas com menos de $20 \%$ de quartzo e com textura fina/média.

\section{REFERÊNCIAS}

BEST MG. 1982. Igneous and Metamorphic Petrology. San Francisco: W.H. Freeman and Company. 630p.

CERMAK V \& RYBACH L. 1982. Thermal properties. In: ANGENHEISTER G. (Ed.). Landolt-Börnstein numerical Data and Functional relationships in science and technology. New series; Group V. Geophysics, vol. 1 Physical Properties of Rocks. Springer-Verlag Berlin. Heidelberg. New York. p. $305-371$.

CLAUSER C \& HUENGES E. 1995. Thermal Conductivity of Rocks and Minerals. AGU Handbook of Physical Constants. American Geophysical Union. Reference Shelf 3. p. 105-126.

DIMENT WH \& PRATT HR. 1988. Thermal conductivity of some rockforming minerals: a Tabulation, U.S.G.S. Open-File Report, Denver Co. p. 88-690.

FIGUEIREDO ERH. 2006. Condutividade Térmica de Rochas: Uma aplicação para Granitos Ornamentais. Dissertação de Mestrado, UFRN, p. 91.

GOMES AJL \& HAMZA VM. 2005. Geothermal gradient and heat flow in the state of Rio de Janeiro. Rev. Bras. Geof., 23(4): 325-347. 
HORAI K. 1971. Thermal Conductivity of Rock-Forming Minerals. J. Geophys. Res., 76(5): 1278-1308.

HUTCHISON CS. 1974. Laboratory Handbook of Petrographic Techniques. Ed. John Wiley \& Sons. 527 p.

INCROPERA FP \& WITT DP. 1981. Fundamentos de Transferência de Calor e de Massa, Livros Técnicos e Científicos Editora S.A., São Paulo. Cap. 1, p. 2-14.

MOORES EM \& TWISS RJ. 1995. Tectonics. Ed. W.H. Freeman and
Company. $415 p$.

SCHÖN JH. 1996. Physical Properties of Rocks: Fundamentals and principles of petrophysics. Ed. Pergamon. Cap. 8, p. 323-378.

STRECKEISEN AL. 1976. To Each Plutonic Rock its Proper Name. Earth Sci. Rev., 12: 1-33.

WINKLER HGF. 1977. Petrogênese das Rochas Metamórficas. Ed. Edgard Blücher Ltda. 254 p.

\section{NOTAS SOBRE OS AUTORES}

Edgar Romeo Herrera de Figueiredo é Geólogo pela Universidade Federal do Rio Grande do Norte (2004). Atuou como bolsista de iniciação científica (CNPq 2001 a 2002; ANP - 2002 a 2004). É Mestre (2006) pelo Programa de Pós-graduação em Geodinâmica e Geofísica da Universidade Federal do Rio Grande do Norte, onde desenvolveu a dissertação intitulada "Condutividade Térmica de Rochas: uma aplicação para Granitos Ornamentais" onde visa avaliar parâmetros térmicos em rochas e sua aplicabilidade como novo parâmetro tecnológico.

Antonio Carlos Galindo é Geólogo e Mestre em Geociências pela UFPE (1973 e 1982), Doutor pela UFPA (1993), com Pós-Doutorado pela Universidade Blaise Pascal, Clermont-Ferrand, França (1998). Atua na área de Petrografia, Petrologia e Geocronologia de Rochas Ígneas Plutônicas, com ênfase no estudo de Rochas Granitóides. Começou sua carreira como Professor dos Cursos Técnicos de Mineração e Geologia do atual CEFET-RN (1974-1976), posteriormente foi Geólogo da CPRM - Serviço Geológico do Brasil entre 1976-1978, e desde 1978 é professor na UFRN, atuando no Curso de Geologia e no Programa de Pós-Graduação em Geodinâmica e Geofísica.

José Antonio de Morais Moreira é Bacharel em Física (Unicamp, 1971), realizou estudos de pós-graduação em Geofísica (IAG-USP, 1980) e é Doutor em Geofísica pelo PPGG-UFRN (2006). Professor do Departamento de Física da UFRN desde 1976. Seus principais interesses são métodos potenciais, estudos crustais, propriedades físicas de materiais geológicos e processamento de sinais. Publicou 4 artigos em revistas internacionais e apresentou 30 trabalhos em congressos nacionais e internacionais. É membro da Sociedade Brasileira de Geofísica e da American Geophysical Union (AGU).

Fernando Antonio Pessoa Lira Lins é Graduado em Geologia pela Universidade Federal de Pernambuco (1975), trabalhou na CPRM no mapeamento de bacias sedimentares, fez mestrado em Geociências pela Universidade Federal de Pernambuco (1987) e doutorado em Geociências pela Universidade Federal de Pernambuco (2000). Atualmente é Professor Associado I do Departamento de Geologia da Universidade Federal do Rio Grande do Norte. Tem atuado na área de Geociências, com ênfase em Geofísica (Métodos Potenciais), atuando principalmente nos seguintes temas: Província Borborema, Zona Transversal, modelamento de corpos graníticos e bacias sedimentares a partir de dados gravimétricos. 